\title{
Amadis de Gaule. Livre IV (traduction Herberay des Essarts), Edition critique par Luce Guillerm
}

\section{Filippo Fonio}

\section{(2) OpenEdition}

1 Journals

\section{Edizione digitale}

URL: http://journals.openedition.org/studifrancesi/27378

DOI: 10.4000/studifrancesi.27378

ISSN: 2421-5856

\section{Editore}

Rosenberg \& Sellier

\section{Edizione cartacea}

Data di pubblicazione: 31 décembre 2006

Paginazione: 589

ISSN: 0039-2944

\section{Notizia bibliografica digitale}

Filippo Fonio, "Amadis de Gaule. Livre IV (traduction Herberay des Essarts), Edition critique par Luce Guillerm », Studi Francesi [Online], 150 (L | III) | 2006, online dal 30 novembre 2015, consultato il 08 novembre 2020. URL : http://journals.openedition.org/studifrancesi/27378 ; DOI : https://doi.org/ 10.4000/studifrancesi.27378

\section{Questo documento è stato generato automaticamente il 8 novembre 2020}

\section{(c) (1)}

Studi Francesi è distribuita con Licenza Creative Commons Attribuzione - Non commerciale - Non opere derivate 4.0 Internazionale. 


\title{
Amadis de Gaule. Livre IV (traduction Herberay des Essarts), Edition critique par Luce Guillerm
}

\author{
Filippo Fonio
}

\section{NOTIZIA}

Amadis de Gaule. Livre IV (traduction Herberay des Essarts), Edition critique par Luce GUILLERM, Paris, Honoré Champion, («Romans de chevalerie de la Renaissance», 92), 2005, pp. 457.

1 Nello studio che accompagna l'edizione critica della traduzione/adattamento di Nicolas de Herberay des Essarts del quarto libro dell'Amadís de Gaula di Garcí Rodriguez de Montalvo, Luce Guillerm sottolinea le particolarità del volgarizzamento francese rispetto all'antecedente castigliano. I romanzi di Montalvo, autore dei libri quarto e quinto dell'Amadis e rimaneggiatore dei primi tre, circolavano in Spagna e non solo dalla seconda metà del XIV secolo. Herberay lavora alla traduzione del quarto libro fra il 1542 e i primi del 1543, e contemporaneamente al rimaneggiamento dei primi tre e del quinto del ciclo di Amadigi, come si desume dalla fitta rete di analessi e prolessi che collegano i vari libri. Il contesto socio-politico profondamente diverso in cui i due autori si trovano a operare sarebbe alla base delle differenze riscontrabili nelle versioni francese e castigliana del quarto libro, in cui hanno notevole importanza fattori che si prestano ad assurgere a metafore dell'assetto politico e dei rapporti di forza fra le potenze del tempo.

Confrontato ai primi tre libri, questo quarto è caratterizzato da un ridimensionamento dei fattori di dispersione e da un entralacement fortemente semplificato rispetto ai modelli cavallereschi. Appare costituito attorno a tre nuclei narrativi forti, che tendono ad assimilare la materia arturiana e quella troiana di cui la storia di Amadigi si è finora nutrita. Essi sono la grande battaglia fra Lisuart, alleato all'imperatore di Roma, e 
Amadis, con i relativi preparativi militari e diplomatici; la riconciliazione generale suffragata dalle nozze; il passaggio di consegne fra Amadis e il figlio Esplandian, protagonista del libro quinto. Il quarto libro rappresenta dunque la fine della saga dell'eroe eponimo, celebrando nel contempo il trionfo dell'accentramento del potere contro i particolarismi feudali. Già in Montalvo, il cavaliere errante diventa re, a celebrazione della monarchia cristiana dei re cattolici. Questa focalizzazione rivolta da un lato alla diplomazia internazionale, dall'altro alla vita di corte e ai suoi cerimoniali, amplia notevolmente il novero dei materiali a cui gli autori possono fare ricorso, che si estendono agli specula principum e alla trattatistica cortigiana, ma pure alle dottrine politiche del tempo; questo passaggio implica fra le altre cose un accentuarsi della componente pragmatica, machiavellica dei passaggi dedicati alle trattative diplomatiche, e a un superamento della visione moralizzante del diritto regio. Nel passaggio da Montalvo a Herberay, tale processo di desacralizzazione appare ancor più evidente: la solennità delle scene di corte è sostituita da una mondanità leggera, la componente eroico-cavalleresca individuale della guerra rimpiazzata dalla visione logistica e dalla rappresentazione collettiva. Anche i pochi elementi forniti finora bastano a evidenziare come questo quarto libro dell'Amadis si presti a una lettura a chiave. Sviluppando una suggestione già di Mireille Huchon, Guillerm propone, senza del resto farla sua incondizionatamente, l'identificazione di Amadis con François I, dell'imperatore di Roma con Carlo $\mathrm{V}$ e via dicendo. Una lettura di questo tipo si presterebbe del resto non ai soli personaggi, ma anche per esempio a elementi architettonici presenti nelle descrizioni, desunti dalla trattatistica rinascimentale neovitruviana. In filigrana al palazzo di Apolidon (l'episodio più celebre del quarto libro, fino ad assumere valore paradigmatico, ricordato fra gli altri da Montaigne, Noël du Fail, Du Bellay, nonché ripreso da La Fontaine per il suo palazzo di Cupido) sarebbe il castello di Chambord, in un gioco di specchi dove realtà e immaginario appaiono elementi inscindibili di una poetica dell'artificio, che è già quella dell'Hypnerotomachia Poliphili. Mentre nei primi tre libri dell'Amadis Herberay si è trovato ad aggiungere particolari a un testo che doveva parergli scarno, in questo caso il volgarizzatore riduce di un terzo il romanzo di Montalvo.

3 L'edizione critica è condotta sulla princeps (Paris, Denis Janot, 1543). Corredano il testo appendici contenenti le varianti e alcuni brani da Montalvo e dall'Amadis del conte di Tressan, un indice onomastico, un glossario e un indice tematico. 